\title{
In-Vitro Technique For Resistance Evaluation Of Rice Varieties Against Blast Disease (Pyricularia Oryzae Cav.)
}

\author{
Tarkus Suganda*, Puspa Radityo Putri, Gabbi Andria Dwitia Putri \\ Department of Plant Pests and Diseases, Agriculture Faculty, Universitas Padjadjaran, Jatinangor, West Java, \\ Indonesia, 45363 \\ * Corresponding author: tarkus.suganda@gmail.com
}

Received September 26, 2019; revised September 27, 2019; accepted December 16, 2019

\begin{abstract}
Blast, incited by Pyricularia oryzae Cav. is the most yield-limiting disease of rice. Use of resistant varieties is the most suggested tactic for controlling this disease. Therefore, resistant varieties are continuosly developed in rice breeding program. One of the challenges in developing resistant varieties to blast is the testing methods which required the availability of optimum condition for infection and development of disease, especially it has to be done against different races of the fungus. In addition, the duration of test is required long period of time. In order to shorten the test, the in-vitro technique has been studied using inoculation to rice leaf cuts incubated in a petridishes amended with several layer of wetted sterilzed tissue. Tests used four differenet domonant races of the fungus, i.e. 033, 073, 133, and 173, wehereas the rice cultivars used were Kencana Bali (susceptible to all races), Situ Patenggang (resistant and moderately resistant), Arize (moderately resistant to race 073) and PP3, a breeding line. Plants were scored using a pictorial scorring scale of IRRI (1996). The results showed that the in-vitro technique using leaf cuts was able to separate the reaction of the resistant from of the susceptible rice to blast disease. It confirmed the reaction of the result of standard greenhouse test. Cultivar Kencana Bali was consistantly susceptible to ras 173 both in in-vitro, standard greenhouse, and in field. The in-vitro technique was able to speed up the inoculation process, prevent a mix of races and release of races to environment. It also can minimize cost of testing, and speed up the selection process of resistance in plant breeding to develop blast resistant varieties.
\end{abstract}

Key words: in-vitro test, leaf blast, Magnaporthe grisea

\section{ABSTRAK}

Teknik In-Vitro Untuk Evaluasi Ketahanan Varietas Padi Terhadap Penyakit Blas (Pyricularia Oryzae Cav.)

Penyakit blas (Pyricularia oryzae Cav.) merupakan penyakit yang sangat merugikan pada tanaman padi. Taktik pengendalian yang paling dianjurkan adalah dengan penggunaan varietas tahan. Oleh karena itu, pengembangan varietas tahan terhadap penyakit blas terus-menerus dilakukan. Salah satu kendala dalam mengembangkan varietas tahan terhadap penyakit blas adalah metode pengujian ketahanannya yang membutuhkan ketersediaan kondisi optimum untuk terjadinya infeksi dan perkembangan penyakit, terutama karena harus dilakukan terhadap berbagai ras yang ada. Selain itu, durasi penelitiannya juga cukup lama. Untuk menyederhanakan proses pengujian ketahanan, telah diuji coba teknik in-vitro yaitu penginokulasian potongan daun padi yang diinkubasikan di dalam cawan Petri yang diberi kertas saring basah sebagai pelembab. Pengujian menggunakan 4 ras yang dominan, yaitu ras 033, 073, 133, dan 173. Tanaman padi yang diuji terdiri atas var. Kencana Bali (rentan), Situ Patenggang (tahan dan agak tahan), Arize (agak tahan terhadap ras 073), dan PP3, sebuah galur padi yang belum dilepas. Skoring pengamatan menggunakan Pictorial Scoring dari IRRI (1996). Hasil pengujian menunjukkan bahwa metode in-vitro inokulasi potongan daun berhasil mendeteksi perbedaan reaksi ketahanan varietas padi terhadap ras $P$. oryzae yang berbeda. Reaksi yang ditunjukan oleh varietas padi dengan metode ini mengonfirmasi reaksi ketahanan berdasarkan uji inokulasi konvensional di rumah kaca. Varietas Kencana Bali terhadap ras 173 menunjukkan reaksi rentan, baik pada metode inokulasi potongan daun, metode konvensional rumah kaca, maupun lapangan. Metode inokulasi potongan daun dapat mempercepat proses inokulasi, mencegah bercampurnya dan penyebaran ras jamur P.oryzae,menekan biaya pengujian, dan mempercepat proses seleksi ketahanan pada pemuliaan tanaman untuk mendapatkan tanaman padi yang tahan terhadap blas.

Kata kunci: uji in-vitro, penyakit blas daun, Magnaporte grisea

\section{PENDAHULUAN}

Penyakit blas yang disebabkan oleh jamur Pyricularia oryzae Cav. (sinonim: Magnaporthe oryzae) merupakan penyakit utama pada tanaman padi di seluruh dunia. Jamur patogen ini dilaporkan menyerang tanaman padi di 80 negara dan menyebabkan kehilangan hasil sebesar 10-30\% dan bahkan sampai $80 \%$ jika menyerang leher malai
(Watkinson, et al., 2016). Kerugian yang ditimbulkannya per tahun rata-rata mencapi US\$70 milyar (Scheuermann et al. 2012). Di daerah endemik penyakit blas, seperti di Sukabumi Jawa Barat, intensitas penyakitnya pada varietas rentan Ciherang, dilaporkan mencapai $55,60 \%$ pada daun dan $37,75 \%$ pada leher malai (Suganda dkk., 2016). Walaupun fungisida sintetik tersedia, jamur ini memiliki 
kemampuan mengembangkan diri menjadi resisten terhadap bahan aktif fungisida dengan membentuk ras-ras baru. Taktik pengendalian yang paling efektif adalah dengan penggunaan varietas tahan (Sudir dkk., 2014). Oleh karena itu pengembangan varietas tahan terus-menerus dilakukan di berbagai negara.

Salah satu kendala dalam mengembangkan varietas tahan terhadap penyakit blas adalah metode pengujiannya yang cukup rumit, lama dan mahal. Pertama, jamur $P$. oyzae memiliki berbagai ras yang umumnya berkaitan dengan lokasi. Dilaporkan sampai tahun 2013, di Indonesia telah ditemukan adanya 30 ras $P$. oryzae yang tersebar terutama di Pulau Jawa (Sudir dkk., 2014) dengan ras-ras yang paling dominan adalah 033, 073, 133, dan 173 (Indrayani dkk., 2013). Oleh karena pengujian ketahanan varietas dan calon varietas harus dilakukan terhadap semua ras yang ada, maka jika pengujian dilakukan di lapangan, pengujian harus dilakukan secara multilokasi di tempat-tempat ras-ras tersebut berada. Hal ini tentu sangat mahal. Ketahanan terhadap blas merupakan prasyarat dilepasnya calon varietas berdasarkan Standar Operasional Pengujian Varietas (Kementerian Pertanian Republik Indonesia, 2018).

Oleh karena sulitnya pengujian lapangan terhadap berbagai ras jamur $P$. oryzae, Kementerian Pertanian Republik Indonesia menerbitkan Prosedur Operasional Standar Pengujian Tahun 2018 yang mengharuskan pengujian ketahanan varietas padi terhadap penyakit blas dilakukan di rumah kaca, menggunakan keempat ras dominan yang diisolasi dari lokasinya masing-masing. Namun, metode pengujian ini pun bukan tanpa masalah, karena dibutuhkan jumlah benih yang cukup banyak (15 tanaman per plot per ulangan untuk setiap ras yang berbeda). Sementara itu, ketersediaan benih sering menjadi kendala bagi para pemulia tanaman. Sebagaimana diketahui, pada tahap-tahap awal proses pemuliaan tanaman, jumlah benih yang dihasilkan sisanya masih sangat sedikit.

Pengujian ketahanan terhadap setiap ras juga harus dilakukan secara terpisah karena ras jamurnya tidak boleh bercampur. Pada pengujian di rumah kaca juga harus diciptakan kondisi optimum agar infeksi dapat terjadi. Kondisi optimum tersebut adalah berupa tersedianya ruang pengabutan atau kondensasi selama 48 jam terus-menerus (minimum $\mathrm{RH} 98 \%$ pada temperatur $26-28^{\circ} \mathrm{C}$ ), yang kemudian harus diikuti oleh penyimpanan di ruang inkubasi selama seminggu.

Sementara itu, beberapa peneliti melaporkan bahwa inokulasi tanaman padi dengan jamur $P$. oryzae dapat dilakukan secara in-vitro (Challagulla, et al., 2015; Takahashi, et al., 2009). Namun belum diketahui apakah teknik in-vitro ini dapat membedakan varietas padi yang tahan dari varietas padi yang rentan. Percobaan ini dimaksudkan untuk mengetahui keefektifan teknik inokulasi in-vitro jamur $P$. oryzae dalam membedakan derajat ketahanan varietas padi terhadap jamur $P$. oryzae.

\section{BAHAN DAN METODE}

Dalam pengujian ini, digunakan empat ras dominan jamur $P$. oryzae, yaitu ras $003,073,133$, dan 173. Isolat kelima ras diperoleh dari Balai Penelitian Padi di Muara Bogor. Pengujian dilakukan terhadap empat varietas padi yang sudah banyak ditanam yaitu Situ Patenggang (memiliki resistensi terhadap ras tertentu), Kencana Bali (rentan terhadap semua ras dominan), Arize (agak tahan terhadap ras 073), dan satu calon varietas milik PT DuPont Agricultural Indonesia, yaitu PP3, yang belum diketahui reaksinya, Situ Patenggang dan Kencana Bali merupakan dua varietas yang menjadi standar pengujian resistensi tanaman padi terhadap blas di Indonesia (Prabawa, dkk., 2015; Lestari, dkk., 2016; Fitriana 2011).

Benih tanaman ditumbuhkan pada medium pot plastik yang diisi tanah steril. Tanaman dibiarkan tumbuh sampai memiliki 5-6 daun yang berkembang sempurna (berumur 21 hari). Daun padi yang telah berkembang sempurna kemudian dipotong sepanjang 3-4 cm setelah sebelumnya dicuci bersih dengan air mengalir, dibilas dengan alkohol $70 \%$ dilanjutkan dengan akuades steril dan dikeringkan dengan cara dilap menggunakan kertas saring steril. Potongan daun kemudian diletakan di dalam cawan Petri menghadap ke atas. Pada bagian alas cawan Petri ditempatkan beberapa lembar kertas saring steril dan dibasahi dengan akuades steril. Di atas kertas saring diletakan dua potong sedotan plastik yang telah disterilkan dengan melapnya dengan alkohol $70 \%$. Penggunaan sedotan plastik adalah untuk meletakkan 3-4 potongan daun, sehingga potongan daun tidak menyentuh kertas saring.

Suspensi $P$. oryzae dipersiapkan dengan menggosok biakan jamur yang ditumbuhkan selama 8 hari pada medium oatmeal agar di tempat gelap . Penggosokan menggunakan batang gelas steril berbentuk huruf L (Kim, et al., 1987). Biakan yang sudah digosok kemudian diinkubasikan lagi di bawah penyinaran lampu UV selama 24 jam untuk pembentukan konidia. Konidia kemudian dipanen dengan menuangkan akuades steril dan menggosoknya dengan gelas batang berbentuk huruf 
L. Kerapatan konidia dalam suspensi kemudian dihitung menggunakan hemasitometer.

Daun-daun padi yang sudah disiapkan di dalam cawan Petri dan siap untuk diinokulasi, ditusuk dengan jarum steril sebanyak 4 tusukan berjarak masing-masing $1 \mathrm{~cm}$ untuk menyediakan lubang kecil bagi proses infeksi. Pada lubang kecil tersebut kemudian diteteskan 1 tetes suspensi jamur $P$. oryzae dengan kerapatan $10^{5}$ konidia per ml yang sudah ditambahi larutan setetes $0,03 \%$ Tween 20, lalu ditutup dengan kapas steril basah. Cawan Petri kemudian ditutup rapat agar kelembabannya terjaga dan lalu diinkubasikan di laboratorium (temperatur 26-28 $\mathrm{C}$ ). Pengamatan dilakukan tujuh hari setelah inokulasi, dengan melepaskan kapas penutupnya. Skoring ketahanan dilakukan dengan menggunakan skoring bergambar dari IRRI 1996 (Gambar 1).

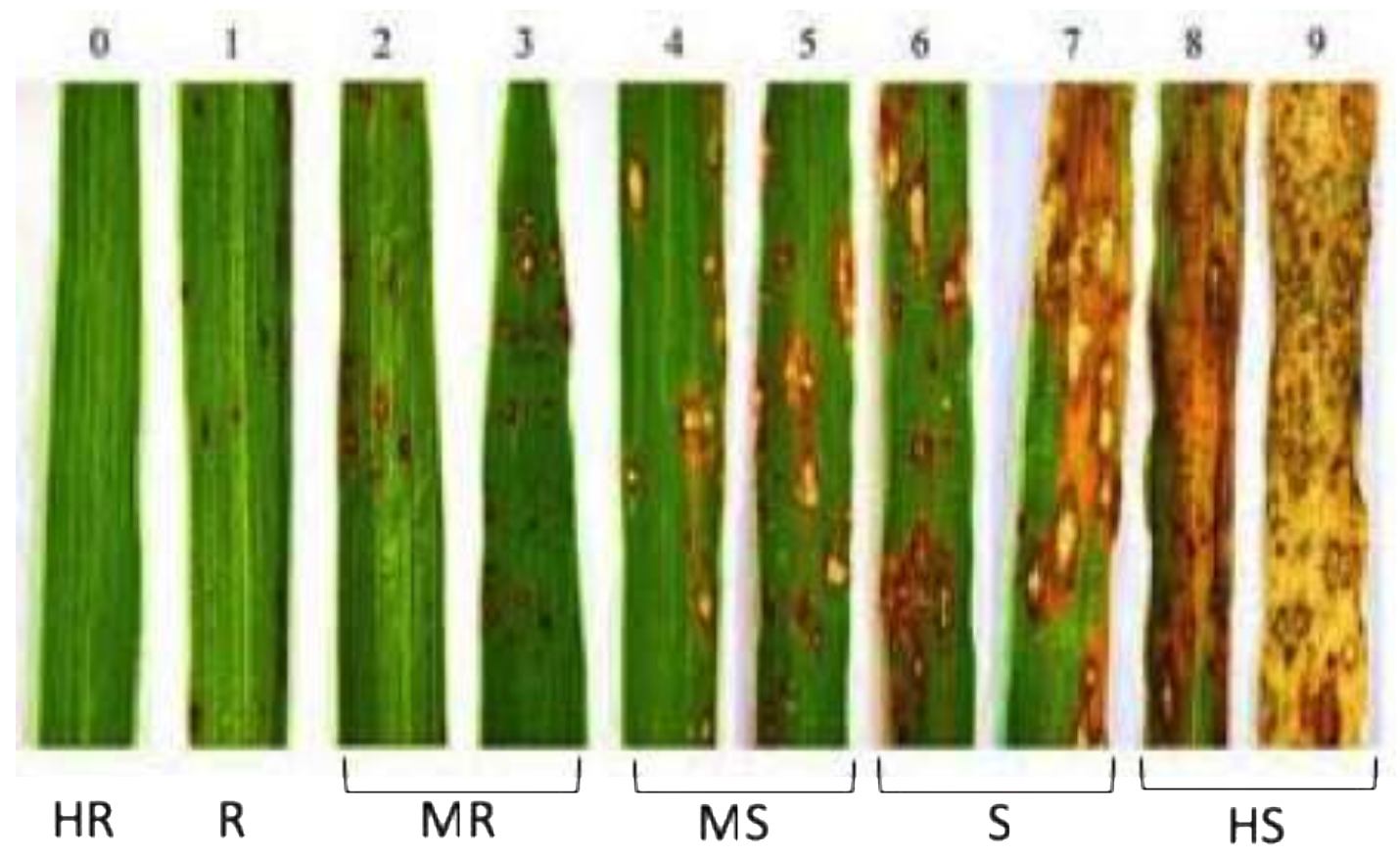

Gambar 1. Skoring bergambar gejala penyakit blas daun padi dengan masing-masing kategori resistensinya IRRI 1996. ( $\mathrm{HR}=$ highly resistant $; \mathrm{R}=$ resistant $; \mathrm{MR}=$ moderately resistant $; \mathrm{MS}=$ moderately susceptible; $\mathrm{S}=$ susceptible, dan HS = highly susceptible). Sumber: Turaidar et al. (2018).

\section{HASIL DAN PEMBAHASAN}

Hasil yang diperoleh dalam penelitian ini mengonfirmasi bahwa teknik inokulasi daun tanaman padi secara in-vitro mampu menghasilkan munculnya gejala blas, sebagaimana dilaporkan oleh (Challagulla et al. 2015; Kim et al. 1987; Takahashi et al. 2009). Penggunaan cawan petri yang diberi kertas tissu basah berhasil menciptakan kondisi yang ideal untuk munculnya gejala penyakit blas. Hal ini memberikan banyak keuntungan dalam menguji reaksi resistensi tanaman padi terhadap blas, karena kelembaban menjadi terkontrol, sementara biayanya murah

Hipotesis yang ingin dibuktikan dalam pengujian ini adalah bahwa teknik penginokulasian in vitro akan dapat membedakan reaksi tanaman padi tahan dari tanaman padi yang rentan ternyata terbukti. Kultivar Kencana Bali, sebagai salah satu kultivar yang menjadi pembanding rentan dalam pengujian resistensi terhadap blas, terkonfirmasi sebagai rentan terhadap keempat ras jamur P. oryzaei (Gambar 2 kiri atas). Hal ini sesuai dengan yang dilaporkan oleh
Indrayani dkk. (2013), bahwa kultivar Kencana Bali rentan terhadap keempat ras yang diuji. Sementara pada kultivar Situ Patenggang yang juga dilaporkan memiliki derajat ketahanan terhadap beberapa ras tertentu, juga terkonfirmasi dalam pengujian ini. Hasil pengujian secara in-vitro ini menunjukkan bahwa kultivar Situ Patenggang tahan terhadap ras 073, sangat rentan terhadap ras 033 dan 133, dan agak tahan terhadap ras 173 (Gambar 1 kanan bawah).

Hasil pengujian juga mengonfirmasi reaksi ketahanan kultivar Arize yang dalam pengujian ini menunjukkan reaksi agak tahan terhadap ras 073 dan resisten terhadap ras 033, yang sesuai dengan deskripsi varietas yang menyatakan bahwa Arize memiliki reaksi agak tahan terhadap ras 073 (http://rilis.id/varietas-hipa-arize-86-dan-hipa-21-

lahir-setelah-penantian-lama). Sementara itu, PP3 yang merupakan calon varietas dan belum dirilis secara resmi, berrdasarkan hasil uji in-vitro menunjukkan reaksi tahan terhadap ras 033, agak 
tahan terhadap ras 133 dan ras 173, dan agak rentan terhadap ras 073 .

Gambar yang ditampilkan di sini hanya satu cawan Petri untuk setiap ras, tetapi dalam pengujian, masing-masing perlakuan varietas uji terhadap ras tertentu, dilakukan dalam tiga ulangan. Hasilnya

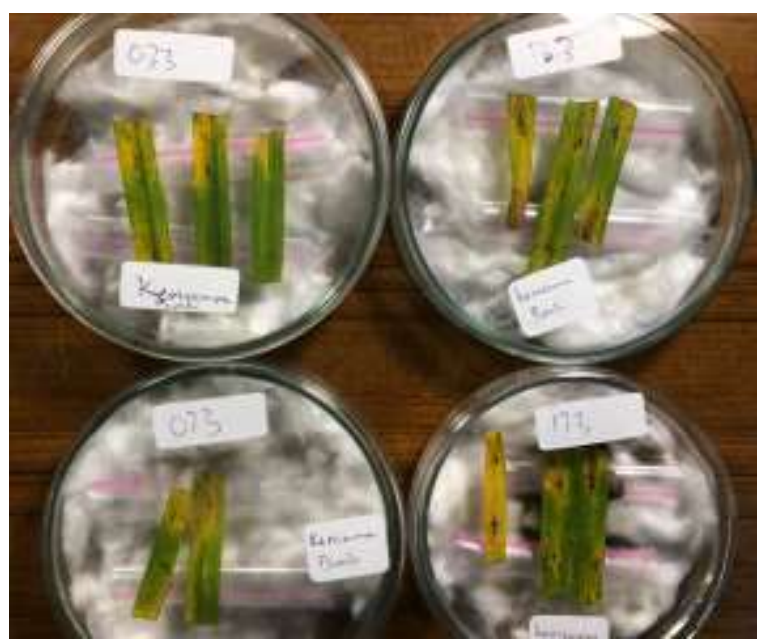

Kencana Bali

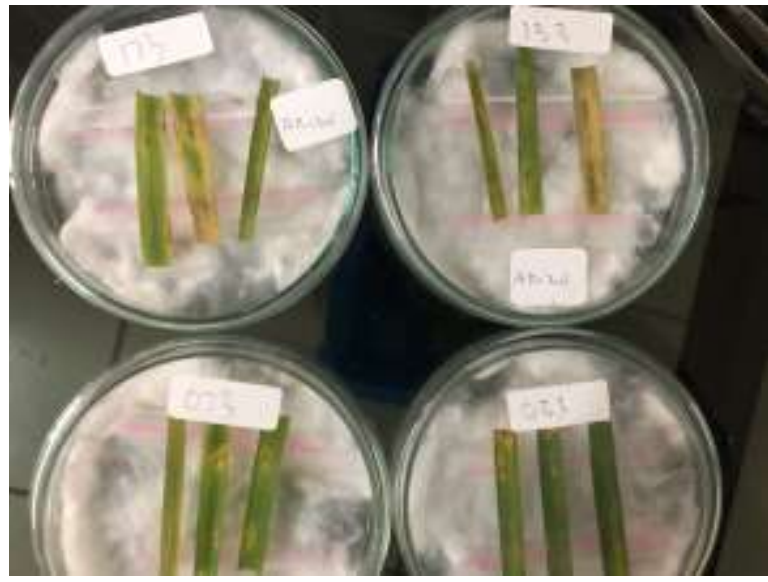

Arize (data tida disajikan) menunjukkan hasil yang relatif seragam antar ulangan. Data tidak dianalisis karena tujuan penelitian ini lebih ditekankan kepada mengetahui apakah uji in vitro dapat membedakan reaksi ketahanan/kerentanan varietas padi terhadap ras-ras $P$. oryzae.

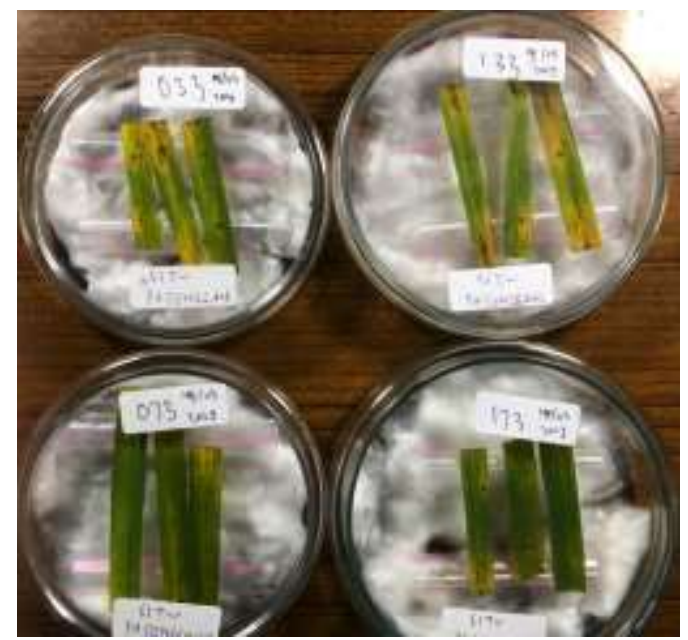

Situ Patenggang

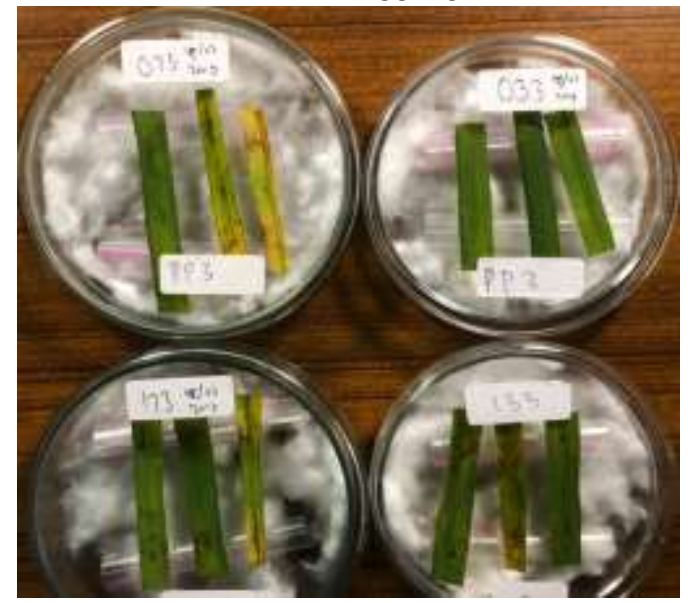

PP3

Gambar 2. Reaksi padi kultivar Kencana Bali, Situ Patenggang dan Arize serta calon varietas PP3 terhadap ras 033, 133, 073 dan 173 dari jamur $P$. oryzae pada pengujian secara in-vitro.

Dibandingkan dengan metode standar pengujian resistensi tanaman padi terhadap penyakit blas di rumah kaca, metode pengujian secara in-vitro menggunakan cawan petri memiliki berbagai keuntungan, yaitu:

1. Mempermudah dan mempercepat waktu pengujian.

Walaupun waktu yang dibutuhkan untuk menumbuhkan bahan tanaman uji antara metode standar dengan metode in-vitro sama, namun pada metode pengujian standar, proses pengondisian selama 48 jam tanaman yang telah diinokulasi di dalam ruang kondensasi ( $\mathrm{RH}$ $>98 \%$, bahkan harus sering harus berupa semburan air, dapat dihilangkan dan diganti dengan ruang lembab di dalam cawan Petri. Ruang kondensasi pasti memerlukan adanya mesin pengabut yang dijalankan dengan aliran listrik. Jika aliran listrik terputus maka proses kondensasi yang diperlukan untuk terjadinya perkembangan infeksi dapat menjadi gagal. Sementara pada cawan petri, tidak diperlukan aliran listrik dan kelembaban dapat dipertahankan secara stabil. Sementara itu, setelah masa kondensasi, tanaman uji harus dipindahkan ke rumah kaca dan dipeliharan selama 7 hari sebelum tanaman diamati. Dalam uji in-vitro, Petridish tetap berada di laboratorium dan gejala dapat diamati. Dengan demikian, metode in-vitro dapat mempercepat dan menyederhanakan proses pengujian. 
2. Mengurangi resiko tercampurnya ras jamur $P$. oryzae di rumah kaca.

Pengujian terhadap setiap ras harus dilaksanakan secara terpisah. Hal ini menyebabkan pada metode pengujian standar, tanaman uji harus diuji terhadap setiap ras secara bergiliran. Artinya, pengujian terhadap ras lain, harus menunggu sampai pengujian terhadap ras sebelumnya selesai dilaksanakan, kecuali tersedia beberapa ruang rumah kaca dan ruang kondensasi yang cukup banyak. Hal ini tidak menjadi masalah pada pengujian menggunakan uji invitro. Pada pengujian in-vitro, pengujian terhadap semua ras dapat dilakukan secara paralel dengan kemungkinan tercampurnya ras menjadi sangat minimal. Untuk mencegah jamur patogen $P$. oryzae menyebar ke lingkungan rumah kaca, tanaman uji yang sudah selesai digunakan harus dimusnahkan. Hal ini cukup merepotkan jika jumlah tanaman ujinya banyak. Berbeda dengan uji in-vitro, tanaman ujinya hanya berupa potongan-potongan daun yang volumenya lebih sedikit sehingga lebih mudah dalam pemusnahannya.

3. Mengefisiensikan jumlah inokulum dan tanaman uji.

Tanaman uji pada metode standar, memerlukan jumlah tanaman yang lebih banyak. Setiap perlakuan (berupa tanaman lengkap pada pot percobaan, menurut SOP Kementerian Pertanian, jumlahnya minimum 15 tanaman. Jumlah tanaman akan lebih banyak lagi sesuai dengan jumlah ulangan. Semakin banyak jumlah pot, semakin besar ruang kondensasi yang harus disediakan. Hal ini baru untuk satu ras. Jika digunakan 4 ras $P$. oryzae, maka jumlah tanaman uji menjadi lebih banyak lagi. Banyaknya jumlah tanaman uji berakibat juga ke jumlah inokulum yang harus disediakan. Untuk keperluan inokulasi, umumnya diperlukan kerapatan konidia $10^{5} \mathrm{konidia} / \mathrm{ml}$. Semakin banyak tanaman uji, semakin banyak volume inokulum yang harus disediakan.Selain itu, jumlah tanaman uji sering menjadi kendala bagi para pemulia tanaman pada tahap awal seleksi hasil persilangan, yang biasanya jumlah benihnya masih sangat terbatas. Bagi pemulia tanaman, jumlah benih menjadi faktor yang sangat diperhitungkan. Dengan lebih sedikitnya jumlah tanaman yang diperlukan dalam uji in-vitro, hal ini sangat menguntungkan bagi pemulia tanaman yang ingin melakukan uji resistensi hasil persilangan padinya pada tahap awal pemuliaan.

\section{KESIMPULAN}

Berdasarkan hasil pengujian dapat disimpulkan bahwa teknik inokulasi in-vitro dapat digunakan untuk menguji respon ketahanan atau kerentanan varietas padi terhadap berbagai ras jamur $P$. oryzae. Teknik ini lebih murah, lebih mudah, menggunakan jumlah benih lebih sedikit, dan lebih cepat, dibandingkan dengan pengujian rumah kaca standar karena menghilangkan beberapa tahapan perlakuan. Dengan teknik ini, ras-ras tidak akan tercampur dan menyebar keluar rumah kaca. Daun tanaman bahan percobaan dapat dihancurkan dengan lebih mudah. Oleh karena itu, teknik ini dapat disarankan untuk digunakan dalam pengujian reaksi resistensi/kerentanan varietas atau calon varietas terhadap penyakit blas.

\section{UCAPAN TERIMA KASIH}

Ucapan terima kasih disampaikan kepada Pimpinan Balai Penelitian Padi di Sukamandi atas penyediaan benih padi Kencana Bali dan Situ Patenggang dan Balai Penelitan Padi di Muara Bogor atas ras-ras isolat $P$. oryzae yang digunakan. Terima kasih juga kepada PT DuPont Agricultural Products Indonesia yang mengizinkan salah satu calon varietas padinya (PP31) digunakan dalam pengujian ini.

\section{DAFTAR PUSTAKA}

Challagulla, V., S. Bhattarai, \& D.J. Midmore. 2015. In-vitro vs in-vivo inoculation: Screening for resistance of Australian rice genotypes against blast fungus. Rice Sci. 22:132-137.

Fitriana, Y. 2011. Uji Ketahanan 48 Galur Padi Terhadap Penyakit Blast (Pyricularia oryzae) RAS 001.

Indrayani, S., A. Nasution, \& E.S. Mulyaningsih, 2013. Analisis ketahanan padi gogo dan padi sawah (Oryza sativa L) terhadap empat ras penyakit blas (Pyricularia grisea Sacc). J. Agric. 3:53-62.

Kim, K. D., B.K. Hwang, \& Y.J. Koh. 1987. Evaluation of Rice Cultivars under Greenhouse Conditions for Adult-Plant Resistance to Pyricularia oryzae. J. Phytopathol. 120:310-316.

Lestari, A., U. Widyastuti, \& W. Enggarini. 2016. Uji Virulensi 100 Isolat Cendawan Blas (Pyricularia oryzae Cavara) terhadap Satu Set Varietas Padi Diferensial Indonesia. J. Agrotek Indones. 1:37-46.

Prabawa, P. S., I. Yulianah, \& N. Basuki. 2015. Uji Ketahanan 10 Genotip Padi Merah (Oryza Sativa L .) Terhadap Penyakit Blas Daun ( Pyricularia oryzae Cav .) Ras 173. J. Produksi Tanam. 3:496-502.

Scheuermann, K.K., J.V. Raimondi, R. Marschalek, A. De Andrade, \& E. Wickert. 2012. Magnaporthe oryzae Genetic Diversity and Its Outcomes on the Search for Durable Resistance. In The Molecular Basis of Plant Genetic Diversity, ed. M Caliskan. Shanghai: INTECH, p. 331-356. Available at: www.interchopen.com. 
Sudir, A., Santoso, \& B. Nuryanto. 2014. Penyakit Blas (Pyricularia grisea) dan Strategi Pengendaliannya pada Tanaman Padi. Iptek Tanam. Pangan. 9:85-96 Available at: http://www.peipfi-komdasulsel.org/wpcontent/uploads/2011/06/37.-PENYAKITBLAS-Pyricularia-grisea-JohanisTandiabang.pdf.

Suganda, T., E. Yulia, F. Widiantini, \& Hersanti. 2016. Intensitas penyakit blas (Pyricularia oryzae Cav .) pada padi varietas Ciherang di lokasi endemik dan pengaruhnya terhadap kehilangan hasil [Disease intensity of blast disease (Pyricularia oryzae Cav.) of Ciherang rice variety at the endemic location and. J. Agrik. 27:154-159.
Takahashi, W., Y. Miura, \& T. Sasaki, 2009. A novel inoculation method for evaluation of grey leaf spot resistance in Italian ryegrass. J. Plant Pathol. 91:171-176.

Turaidar, V., M. Reddy, R. Anantapur, N. Dalawai, \& H.K.M. Kumar. 2018. Screening of traditional rice varieties (TRVs) for blast resistance. J. Pharmacogn. Phytochem. 7:1384-1388 Available at: http://www.phytojournal.com/archives/2018/ vol7issue1/PartS/7-1-4-893.pdf.

Watkinson, S.C., L. Boddy, \& N.P. Money. 2016. The Fungi. 3rd ed. Amsterdam: Elsevier Academic Press.

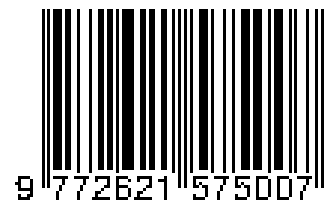

